\title{
Crataegus pinnatifida Bunge Inhibits RANKL-Induced Osteoclast Differentiation in RAW 264.7 Cells and Prevents Bone Loss in an Ovariectomized Rat Model
}

\author{
Minsun Kim, MinBeom Kim, Jae-Hyun Kim, SooYeon Hong, Dong Hee Kim, Sangwoo Kim, \\ Eun-Young Kim, Hyuk-Sang Jung $(\mathbb{D}$, and Youngjoo Sohn $\mathbb{i}$
}

Department of Anatomy, College of Korean Medicine, Kyung Hee University, Seoul 02447, Republic of Korea

Correspondence should be addressed to Hyuk-Sang Jung; jhs@khu.ac.kr and Youngjoo Sohn; youngjoos@khu.ac.kr

Received 27 January 2021; Revised 21 February 2021; Accepted 8 March 2021; Published 30 March 2021

Academic Editor: Reza B. Jalili

Copyright (C) 2021 Minsun Kim et al. This is an open access article distributed under the Creative Commons Attribution License, which permits unrestricted use, distribution, and reproduction in any medium, provided the original work is properly cited.

\begin{abstract}
Osteoporosis is characterized by a decrease in bone microarchitecture with an increased risk of fracture. Long-term use of primary treatments, such as bisphosphonates and selective estrogen receptor modulators, results in various side effects. Therefore, it is necessary to develop alternative therapeutics derived from natural products. Crataegus pinnatifida Bunge (CPB) is a dried fruit used to treat diet-induced indigestion, loss of appetite, and diarrhea. However, research into the effects of CPB on osteoclast differentiation and osteoporosis is still limited. In vitro experiments were conducted to examine the effects of CPB on RANKLinduced osteoclast differentiation in RAW 264.7 cells. Moreover, we investigated the effects of CPB on bone loss in the femoral head in an ovariectomized rat model using microcomputed tomography. In vitro, tartrate-resistant acid phosphatase (TRAP) staining results showed the number of TRAP-positive cells, and TRAP activity significantly decreased following CPB treatment. $\mathrm{CPB}$ also significantly decreased pit formation. Furthermore, CPB inhibited osteoclast differentiation by suppressing NFATc1, and c-Fos expression. Moreover, CPB treatment inhibited osteoclast-related genes, such as Nfatc1, Ca2, Acp5, mmp9, CtsK, Oscar, and Atp6v0d2. In vivo, bone mineral density and structure model index were improved by administration of CPB. In conclusion, $\mathrm{CPB}$ prevented osteoclast differentiation in vitro and prevented bone loss in vivo. Therefore, $\mathrm{CPB}$ could be a potential alternative medicine for bone diseases, such as osteoporosis.
\end{abstract}

\section{Introduction}

Osteoporosis is characterized by a decrease in bone microarchitecture and an increased risk of fracture [1]. Bone remodeling is balanced between bone formation by osteoblasts and bone resorption by osteoclasts [2]. However, the excessive activity of osteoclasts induces osteoporosis, rheumatoid arthritis, and periodontitis. Thus, the inhibition of the osteoclast differentiation and its activity plays a role in the treatment strategy of osteoporosis.

Osteoclasts are giant, multinucleated cells derived from hematopoietic stem cells. Receptor activator of nuclear factor kappa- $\beta$ ligand (RANKL) is essential for osteoclast differentiation $[3,4]$. The binding of RANKL to RANK stimulates tumor necrosis factor receptor (TNFR)-associated factor 6
(TRAF6), activating mitogen-activated protein kinase (MAPKs) and nuclear factor kappa- $\beta$ (NF- $\kappa \mathrm{B})$. As a result, it induces the expression of NFATc1 and c-Fos, known as essential transcription factors for osteoclast differentiation. These transcription factors induce the expression of osteoclast-related genes such as tartrate-resistant acid phosphatase (TRAP), carbonic anhydrase II (CA2), matrix metallopeptidase 9 (MMP-9), ATPase $\mathrm{H}+$ transporting lysosomal $38 \mathrm{kDa} \mathrm{V0}$ subunit d2 (ATP6v0d2), osteoclast associated receptor (OSCAR), and cathepsin K (CTK) [5, 6].

Bisphosphonate and selective estrogen receptor modulators (SERMs) are frequently used as treatments. However, long-term treatment of these agents causes side effects such as Paget's disease of bone, breast cancer, prostate cancer, hot flashes, and night sweats [7-10]. Therefore, there is a need 
for integrating complementary and alternative medicines for osteoporosis based on natural products with few side effects. Consequently, the importance of developing an alternative treatment for osteoporosis has increased currently.

Crataegus pinnatifida Bunge (CPB) is the dried fruit of Crataegus pinnatifida Bung, called "Sansa" in Korea [11]. Previous studies have shown that CPB has antioxidant and anti-inflammatory effects $[12,13]$. Chlorogenic acid is the major component of Crataegus pinnatifida Bunge and has an inhibitory effect on osteoclast differentiation induced by RANKL [14]. It has also been linked to anti-inflammatory and antioxidant effects $[15,16]$. Osteoporosis is caused by endocrine, metabolic, and mechanical factors. Furthermore, recent studies have shown that the risk of developing osteoporosis is increased in inflammatory conditions $[17,18]$. Therefore, we hypothesize that $\mathrm{CPB}$ may have a positive effect on bone metabolism.

In this study, we investigated the in vitro effects of $\mathrm{CPB}$ on RANKL-induced osteoclast differentiation. In addition, we also investigated the in vivo effects of $\mathrm{CPB}$ on bone loss in an ovariectomized (OVX) model.

\section{Materials and Methods}

2.1. Chemicals and Reagents. RANKL was purchased from PeproTech (London, UK). Dulbecco's modified eagle medium (DMEM) was purchased from Welgene (Daejeon, Korea). Minimum Essential Medium Eagle alpha-modification ( $\alpha$-MEM), penicillin/streptomycin (P/S), Dulbecco's phosphate buffered saline (DPBS), and normal serum were purchased from Gibco (Gaithersburg, MD). Fetal bovine serum (FBS) was supplied by Atlas Biologicals (Fort Collins, CO). TRAP staining kit, bicinchoninic acid (BCA) solution, and $17 \beta$-estradiol $\left(\mathrm{E}_{2}\right)$ were obtained from Sigma Aldrich (St. Louis, MI, USA). Cell Titer $96^{\circledR}$ AQueous nonradioactive cell proliferation assay (MTS) was obtained from Promega (Madison, WI, USA). Osteo assay surface multiple well plate was obtained from Corning Inc. (Corning, NY, USA). Anti$\beta$-actin (cat. no. sc-8432) and anti-c-Fos (cat. no. sc-447) were supplied Santa Cruz Biotechnology (Santa Cruz, CA, USA). Anti-NFATc1 (cat. no. 556602) was supplied by BD Pharmingen (San Diego, CA, USA). Secondary antibodies (cat. no. 111-035-045, 115-035-062) were supplied by Jackson ImmunoResearch (West Grove, PA, USA). Polymerase chain reaction (PCR) primers were obtained from Genotech (Daejeon, Korea). SuperScript II Reverse transcription kit and SYBR green were obtained from Invitrogen (Carlsbad, CA, USA). Taq polymerase was obtained from Kapa Biosystems (Woburn, MA, USA). Avidin-biotin complex (ABC) kit and 3,3'-diaminobenzidine (DAB) were obtained from Vector Laboratories, Inc. (Burlingame, CA, USA). All reagents used in the experiments were of analytical grade.

2.2. Preparation of $C P B$ Extract. $C P B$ was obtained from Omni Herb Inc. (Seoul, Korea). The sample extract was prepared by decocting $600 \mathrm{~g}$ dried herb with $6 \mathrm{~L}$ boiling distilled water $\left(\mathrm{dH}_{2} \mathrm{O}\right)$ for $2 \mathrm{~h}$. Next, the filtrate was evaporated using a vacuum evaporator and freeze-dried into powder. The yield from the dried herbs was $39.6 \%$ (freezedried powder: $237.8 \mathrm{~g}$ ), and the powder was subsequently stored at $-20^{\circ} \mathrm{C}$.

\subsection{High-Performance Liquid Chromatography Analysis.} Quantitative analysis of main components in CPB was performed using an A Waters 2695 system equipped with a Waters 2487 Dual $\lambda$ absorbance detector and X-bridge C18 Column $(250 \mathrm{~mm} \times 4.6 \mathrm{~mm}, 5 \mu \mathrm{m})$. CPB dissolved in $\mathrm{dH}_{2} \mathrm{O}$. $\mathrm{CPB}$ was passed through a $0.2-\mu \mathrm{m}$ membrane filter and $10 \mu \mathrm{L}$ volume of the filtrate was injected into the HPLC column. The mobile phases are composed of solvent $\mathrm{A}$ (acetonitrile) and solvent $\mathrm{B}\left(\mathrm{H}_{2} \mathrm{O}\right.$ ( $1 \%$ acetic acid)). The detection time was $0-30 \mathrm{~min}$. The flow rate was $1.0 \mathrm{~mL} / \mathrm{min}$.

2.4. Cell Culture and Cell Viability. The RAW 264.7 cells were purchased from Korean Cell Line Bank (Seoul, Korea). RAW 264.7 cells were cultured in DMEM supplemented with $1 \% \mathrm{P} / \mathrm{S}$ and $10 \% \mathrm{FBS}$. The cells were incubated at $37^{\circ} \mathrm{C}$ in a humidified atmosphere of $5 \% \mathrm{CO}_{2}$ (Thermo Fisher, Waltham, MA, USA). The MTS assay was performed to examine the toxicity of CPB on RAW 264.7 cells. RAW 264.7 cells were seeded at a density of $5 \times 10^{3}$ cells/well in a 96-well plate. The $\mathrm{CPB}$ was administered at 125, 250, 500, and $1000 \mu \mathrm{g} / \mathrm{mL}$ for $24 \mathrm{~h}$. Afterwards, $20 \mu \mathrm{L}$ MTS solution was added to the wells for $2 \mathrm{~h}$. The absorbance $(490 \mathrm{~nm})$ was measured by an enzyme-linked immunosorbent assay (ELISA) reader. Results were indicated as a percentage of the control. Cytotoxicity was considered as cell viability less than $90 \%$ of the control.

2.5. TRAP Staining and Pit Assay. RAW 264.7 cells were seeded at a density of $5 \times 10^{3}$ cells/well in 96-well plate. After $24 \mathrm{~h}$, RAW 264.7 cells were differentiated with $\alpha$-MEM supplemented with $1 \%$ P/S, 10\% FBS, and RANKL (100 ng/ $\mathrm{mL})$. The media was changed every 2 days. After 5 days, the osteoclast cells were fixed with $10 \%$ formalin for $10 \mathrm{~min}$ and then stained using a TRAP staining kit, according to the manufacturer's instructions. Afterwards, cells were rinsed with $\mathrm{dH}_{2} \mathrm{O}$ and dried at room temperature. Multinucleated osteoclasts were considered as TRAP-positive cells with three or more nuclei (red color). To measure TRAP activity, differentiation medium was transferred to new 96-well plates and TRAP solution $(4.93 \mathrm{mg} \mathrm{pNPP}+850 \mu \mathrm{L} 0.5 \mathrm{M}$ acetate solution $+150 \mu \mathrm{L}$ tartrate solution) was added to 96 -well plate at $37^{\circ} \mathrm{C}$ for $1 \mathrm{~h}$. TRAP activity was measured at $405 \mathrm{~nm}$ by an ELISA reader. To examine pit formation, RAW 264.7 cells were seeded at a density of $5 \times 10^{3}$ cell/well in a multiple well osteo assay surface plate and incubated for 5 days. Thereafter, the cells were removed using $\mathrm{NaClO}$. The pit area was measured by ImageJ version 1.46 (National Institutes of Health, Bethesda, MD, USA).

2.6. Western Blotting. RAW 264.7 cells were incubated with RANKL and various concentrations of CPB extract (125, 250,500 , and $1000 \mu \mathrm{g} / \mathrm{mL}$ ) for $24 \mathrm{~h}$. Cells were lysed in radioimmunoprecipitation assay (RIPA) lysis buffer (50 mM Tris- 
$\mathrm{Cl}, 150 \mathrm{mM} \mathrm{NaCl}, 1 \% \mathrm{NP}-40,0.5 \%$ sodium deoxycholate, and $0.1 \%$ SDS) consisting of proteinase inhibitors (Sigma Aldrich; Merck KGaA, Darmstadt, Germany) to obtain the protein. Thereafter, total protein quantification was done using BCA assay according to the manufacturer's instructions. The protein samples were separated by $10 \%$ sodium dodecyl sulphate-polyacrylamide gel electrophoresis (SDSPAGE) and transferred onto a nitrocellulose membrane. The membranes were blocked (5\% skim milk) for $1 \mathrm{~h}$ and incubated overnight at $4{ }^{\circ} \mathrm{C}$ with primary antibodies for $\beta$-actin $(1: 1,000)$, NFATc1 $(1: 1,000)$, and c-Fos $(1: 1,000)$. After $24 \mathrm{~h}$, the membranes were incubated with secondary antibodies $(1: 10,000)$ for $1 \mathrm{~h}$ at room temperature. The protein was visualized by enhanced chemiluminescence (ECL) (Whatman plc; GE Healthcare) and protein band densitometry was measured by ImageJ version 1.46. All data were normalized to the $\beta$-actin density.

2.7. Reverse Transcription-Quantitative PCR (RT-qPCR). RAW 264.7 cells were incubated with CPB $(125,250,500$, and $1000 \mu \mathrm{g} / \mathrm{mL})$ for 4 days and the RANKL $(100 \mathrm{ng} / \mathrm{mL})$. Total RNA was extracted from RAW 264.7 cells using TRIzol reagent, according to the manufacturer's instructions. Then, cDNA was synthesized using the reverse transcription kit (Invitrogen, Carlsbad, CA, USA). RT-qPCR was performed with a C1000 Touch ${ }^{\mathrm{TM}}$ thermal cycler (Bio-Rad Laboratories, Hercules, CA, USA) and Taq polymerase. The PCR cycling conditions were initial denaturation cycle at $95^{\circ} \mathrm{C}$ for $5 \mathrm{~min}$, followed by $30-40$ cycles of amplification at $94^{\circ} \mathrm{C}$ for $30 \mathrm{sec}$, annealing at $53-58^{\circ} \mathrm{C}$ for $30 \mathrm{sec}$, and extension at $72^{\circ} \mathrm{C}$ for $30 \mathrm{sec}$. Primers for osteoclast-related genes are described in Table 1. The reaction was electrophoresed on 1-1.2\% agarose gels stained with SYBR. The agarose gel was visualized using $\mathrm{N} \alpha \mathrm{B}^{\mathrm{I}_{\mathrm{TM}}}$ (Neoscience, Suwon, Korea). The expression level of mRNA in the analyzed gene was normalized to the glyceraldehyde-3-phosphate dehydrogenase (GAPDH) using ImageJ version 1.46 .

2.8. Animal Experiments and Induction of OVX Rats. Animal experiments were conducted in accordance with Guidelines for the Care and Use of Laboratory Animals approved by the Committee on Animal Experimentation of Kyung Hee University (KHUASP (SE)-15-101). Female Sprague-Dawley (SD) rats (12 weeks of age) were purchased from Nara Biotech (Seoul, Korea). SD-rats were housed at $22 \pm 2^{\circ} \mathrm{C}$, with a relative humidity of $53-55 \%$ in a $12 \mathrm{~h}$ light-dark cycle. In this study, all animals had ad libitum access to water and food. The SD-rats were acclimatized for one week before surgery. To establish an OVX model, the rats were anesthetized with $100 \%$ oxygen and $5 \%$ isoflurane to remove the ovaries. The sham group did not have their ovaries removed but received the same stress. The rats were divided into five groups $(n=8$ per group) as follows: (1) sham group; sham-operation, treated with $\mathrm{dH}_{2} \mathrm{O},(2)$ OVX group; OVX-induced, treated with $\mathrm{dH}_{2} \mathrm{O}$, (3) $\mathrm{E}_{2}$ group; OVX-induced, treated with $100 \mu \mathrm{g} / \mathrm{kg} 17 \beta$-estradiol, (4) CPB-L group; OVX-induced, treated with $13.2 \mathrm{mg} / \mathrm{kg} \mathrm{CPB}$, and (5) $\mathrm{CPB}-\mathrm{H}$ group;
OVX-induced, treated with $132 \mathrm{mg} / \mathrm{kg}$ CPB. The dose of $\mathrm{CPB}$ was calculated as follows: In Korean medicine, the recommended single dose for an adult is $8 \mathrm{~g} / 60 \mathrm{~kg}$, effectively equating to $3.168 \mathrm{~g}$ (yield, 39.6\%) CPB powder of $8 \mathrm{~g}$ dried herbs. Therefore, the CPB-L group was administered $13.2 \mathrm{mg} / \mathrm{kg}$ CPB. Since the metabolism of rodents is faster than that of humans, the high-dose group was administered 10 times the concentration of the lowdose group [19]. Thus, CPB-H group was administered $132 \mathrm{mg} / \mathrm{kg}$ CPB. To prevent infection at the surgical site, all rats received injections with $4 \mathrm{mg} / \mathrm{kg}$ gentamicin for 3 days after surgery. $\mathrm{E}_{2}$ and $\mathrm{CPB}$ were dissolved in $\mathrm{dH}_{2} \mathrm{O}$ and administered orally once per day for 8 weeks. Body weights were measured once a week. During the experiments, all animals showed no side effects and exhibited no abnormal behavior. After 8 weeks, the experimental animals were anesthetized with $100 \%$ oxygen and $5 \%$ isoflurane and sacrificed by lethal cardiac puncture and cervical vertebrae dislocation.

2.9. Microcomputed Tomography Analysis. After sacrifice, the femur samples were fixed in $10 \%$ neutral buffered formalin (NBF) at room temperature for $24 \mathrm{~h}$. The femoral head was analyzed using microcomputed tomography (microCT) (SkyScan1176; Bruker Corporation, Kontich, Belgium). Bone microstructure parameters such as bone mineral density (BMD), bone volume/total volume (BV/TV), and structure model index (SMI) were analyzed using NRecon software (SkyScan version 1.6.10.1; Bruker Corporation, Billerica, MA, USA).

2.10. Hematoxylin and Eosin (H®E) Staining. The fixed femur samples were decalcified in ethylenediaminetetraacetic acid (EDTA) for 4 weeks at room temperature. Afterwards, femur samples were dehydrated and embedded in paraffin. Femur samples were sectioned using a rotary microtome (5 $\mu \mathrm{m}$-thick, ZEISS, Oberkochen, Germany), then dried and stained with H\&E. Changes in tissue parameters, such as femoral head area, were observed using an inverted light microscope (magnification, 40x and 100x; Olympus Corporation, Tokyo, Japan). The trabecular area was measured by ImageJ version 1.46 .

2.11. Immunohistochemistry Staining. Sectioned tissues were paraffinized and rehydrated to prepare for immunohistochemistry (IHC). Femur tissue slides were treated with $0.3 \%$ hydrogen peroxide-methanol to inhibit endogenous peroxidase. Subsequently, nonspecific reactions were blocked with normal serum for $1 \mathrm{~h}$ at room temperature. After washing thrice with $\mathrm{PBS}$, sections were incubated with primary antibody at $4^{\circ} \mathrm{C}$ overnight and then incubated with secondary antibodies for $1 \mathrm{~h}$ at room temperature. The tissues were incubated with an $\mathrm{ABC}$ kit for $30 \mathrm{~min}$ at room temperature, followed by staining with $\mathrm{DAB}$ solution and counterstaining with hematoxylin. Histological changes were analyzed using a light microscope (magnification, 100x and 200x). 
Table 1: Primer sequences for RT-qPCR.

\begin{tabular}{|c|c|c|c|c|}
\hline Gene name & Primer sequence $\left(5^{\prime}-3^{\prime}\right)$ & $\operatorname{Tm}\left({ }^{\circ} \mathrm{C}\right)$ & cycle & Accession no \\
\hline MMP-9 (Mmp9) & $\begin{array}{l}\text { F: CGA CTT TTG TGG TCT TCC CC } \\
\text { R: TGA AGG TTT GGA ATC GAC CC }\end{array}$ & 58 & 30 & NM_013599.4 \\
\hline CTK (Ctsk) & $\begin{array}{l}\text { F: AGG CGG CTA TAT GAC CAC TG } \\
\text { R: CCG AGC CAA GAG AGC ATA TC }\end{array}$ & 58 & 26 & NM_007802.4 \\
\hline TRAP (Acp5) & $\begin{array}{l}\text { F: ACT TCC CCA GCC CTT ACT ACC G } \\
\text { R: TCA GCA CAT AGC CCA CAC CG }\end{array}$ & 58 & 30 & NM_007388.3 \\
\hline NFATc1 (Nfatc1) & $\begin{array}{l}\text { F: TGC TCC TCC TCC TGC TGC TC } \\
\text { R: CGT CTT CCA CCT CCA CGT CG }\end{array}$ & 58 & 32 & NM_198429.2 \\
\hline OSCAR (Oscar) & $\begin{array}{l}\text { F: CTG CTG GTA ACG GAT CAG CTC CCC AGA } \\
\text { R: CCA AGG AGC CAG AAC CTT CGA AAC T }\end{array}$ & 53 & 35 & NM_001290377.1 \\
\hline $\mathrm{CA} 2(\mathrm{Ca} 2)$ & $\begin{array}{l}\text { F: CTC TCA GGA CAA TGC AGT GCT GA } \\
\text { R: ATC CAG GTC ACA CAT TCC AGC A }\end{array}$ & 58 & 32 & NM_001357334.1 \\
\hline ATP6v0d2 (Atp6v0d2) & $\begin{array}{l}\text { F: ATG GGG CCT TGC AAA AGA AAT CTG } \\
\text { R: CGA CAG CGT CAA ACA AAG GCT TGT A }\end{array}$ & 58 & 30 & NM_175406.3 \\
\hline GAPDH (Gapdh) & $\begin{array}{l}\text { F: ACT TTG TCA AGC TCA TTT CC } \\
\text { R: TGC AGC GAA CTT TAT TGA TG }\end{array}$ & 58 & 30 & NM_008084.3 \\
\hline
\end{tabular}

2.12. Statistical Analysis. Data are presented as mean\pm standard error (SEM) of the mean for three replicates. Differences between the control and CPB treatment groups were analyzed using one-way ANOVA followed by a Dunnett's post hoc in GraphPad PRISM version 5.01 (GraphPad Software Inc., San Diego, CA, USA). Statistical significance was determined at $p<0.05$.

\section{Results}

3.1. Quantitative Analysis of the CPB Extract. HPLC was used to confirm the main component of CPB [20]. As shown in Figure 1, the retention times of $\mathrm{CPB}$ are identical to the retention times of the chlorogenic acid standards.

3.2. Effect of CPB on RANKL-Induced TRAP Activity and Pit Formation. To determine the cytotoxic effect of CPB, RAW 264.7 cells and osteoclast were treated with CPB concentrations from $125,250,500$, and $1000 \mu \mathrm{g} / \mathrm{mL}$. In this study, none of the CPB concentrations affected cell viability in either RAW 264.7 cells or osteoclasts (Figures 2(a) and 2(b)). To investigate the effect of CPB on RANKL-induced osteoclast differentiation and pit formation, TRAP staining and pit assay was used. RANKL increased the number of TRAPpositive cells and TRAP activity compared with the untreated control group, confirming osteoclast differentiation. $\mathrm{CPB}$ treatment of differentiated osteoclasts decreased the number of TRAP-positive cells and TRAP activity in a dosedependent manner. In addition, the pit area was increased with RANKL treatment, compared to untreated controls, and decreased by $\mathrm{CPB}$ treatment in a dose-dependent manner (Figures 2(c)-2(f)).

3.3. Effect of CPB on RANKL-Induced Expression of NFATc1 and c-Fos. To examine the expression of NFATc1 and c-Fos, we performed western blotting (Figures 3(a) and 3(b)). NFATc1 and c-Fos expression were significantly increased in the RANKL-induced cells compared to the nonstimulated control group. Therefore, the expressions of NFATc1 and c-Fos were suppressed by CPB in a dose-dependent manner.

3.4. Effect of CPB on RANKL-Induced of Osteoclast-Related Genes. To investigate the effect of $\mathrm{CPB}$ on osteoclast-related genes in RANKL-induced RAW 264.7 cells, RT-qPCR was performed. Treatment with RANKL increased the mRNA levels of Nfatc1, Ca2, Acp5, mmp9, CtsK, Oscar, and Atp6v0d2. In contrast, CPB reduced these mRNA levels in a dose-dependent manner, the most effective dose in all instances (Figures 4(a) and 4(b)).

3.5. Effect of $C P B$ on OVX-Induced Models. To analyze the effect of $\mathrm{CPB}$ on OVX-induced postmenstrual osteoporosis, we orally administered $\mathrm{E}_{2}, \mathrm{CPB}-\mathrm{L}$, and $\mathrm{CPB}-\mathrm{H}$ to the OVXinduced rats daily for 8 weeks. As shown in Figure 5(a), the body weight of both treated and untreated OVX-induced rats significantly increased after 3 weeks as compared to that of the sham group. However, there was no significant difference in body weight between the OVX group and $\mathrm{E}_{2}, \mathrm{CPB}-\mathrm{L}$, and $\mathrm{CPB}-\mathrm{H}$, respectively. The uterus weight decreased in the OVX group as compared with that in the sham group (Figure 5(b)). Furthermore, the uterus weight increased in the $\mathrm{E}_{2}$ group as compared with that in the OVX group, with no effect observed in CPB-L and CPB-H, femur weights significantly decreased in the OVX group compared to that in the sham group (Figure 5(c)). However, there was no difference in femur weight between the $\mathrm{E}_{2}, \mathrm{CPB}-\mathrm{L}$, and $\mathrm{CPB}-\mathrm{H}$ groups compared to the OVX group. Tibia weight and ash were decreased in the OVX group compared with the sham group (Figures $5(\mathrm{~d})$ and $5(e))$, though there were no significant differences between $E_{2}$, CPB-L, and CPB-H, compared to the OVX group.

3.6. Effect of $C P B$ on Bone Loss in OVX-Induced Models. In the micro-CT image, the bone density in the femoral head of OVX group was decreased compared with the sham group (Figure 6(a)). Furthermore, $\mathrm{E}_{2}$ and $\mathrm{CPB}-\mathrm{H}$ significantly increased bone density in the femoral head compared with the OVX group. From the results of the bone microstructure 


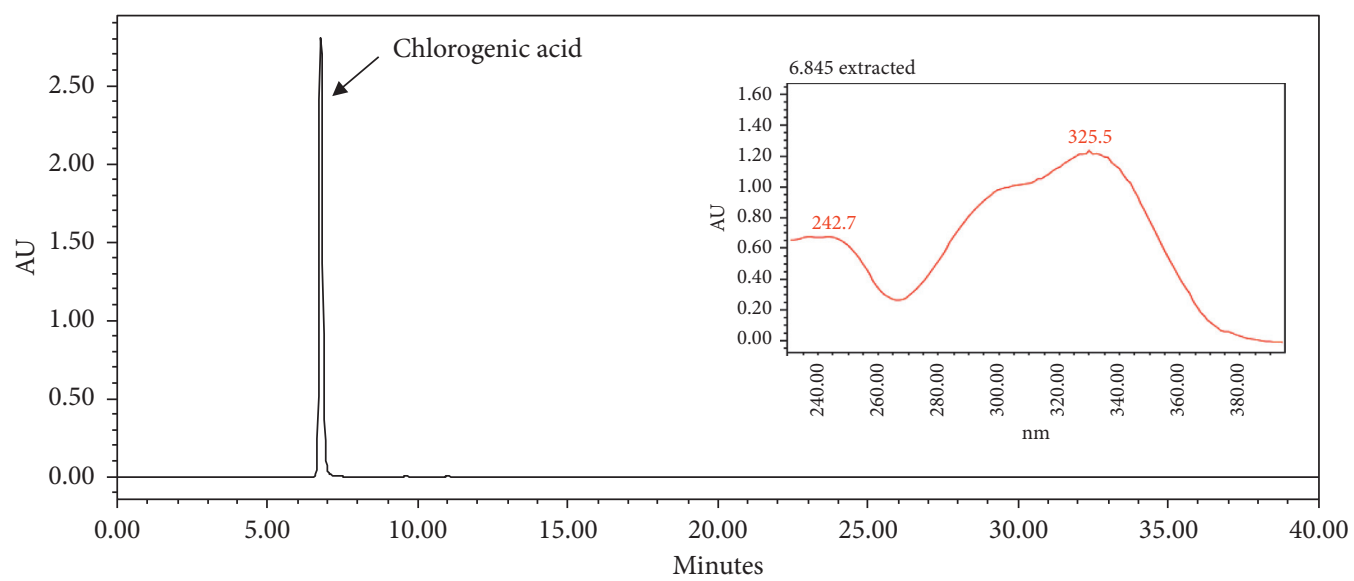

(a)

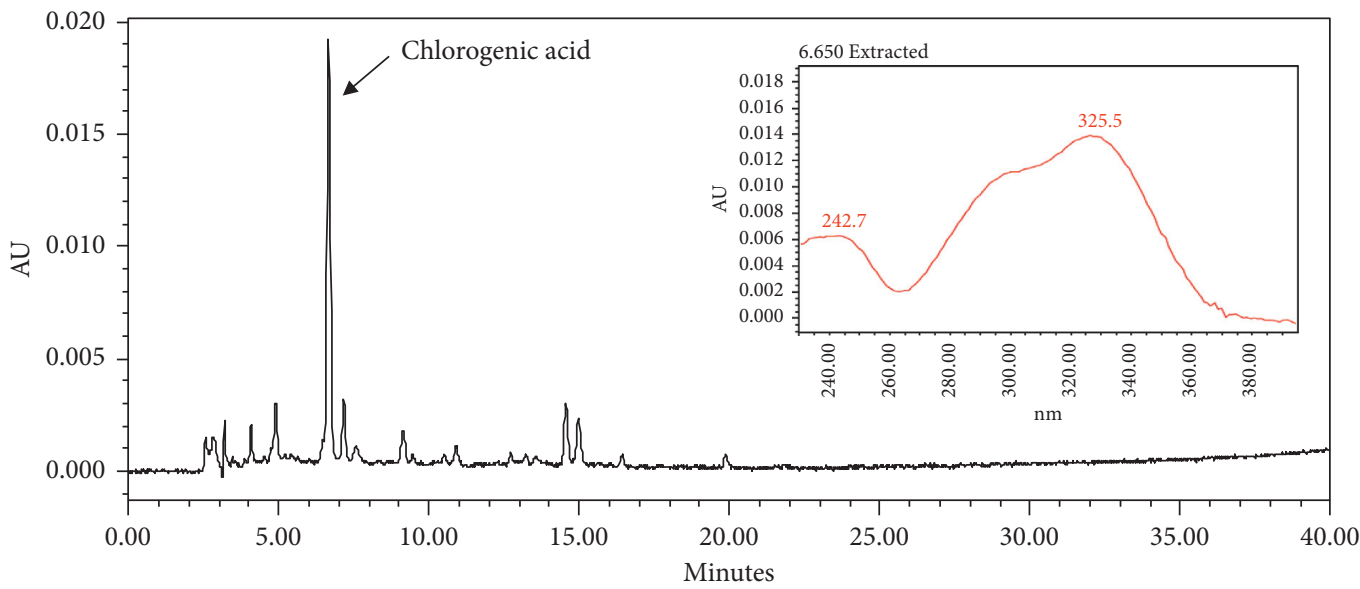

(b)

FIGURE 1: Quantitative HPLC of (a) chlorogenic acid standard and (b) CPB. The HPLC-analysis for standards and sample solutions. (a) Chlorogenic acid standard solution; (b) CPB samples were detected at $330 \mathrm{~nm}$.

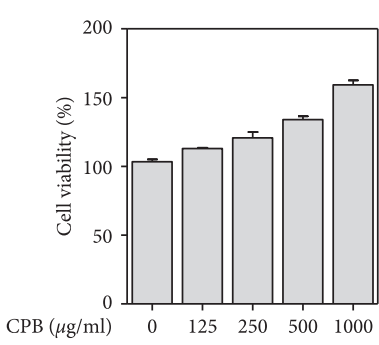

(a)
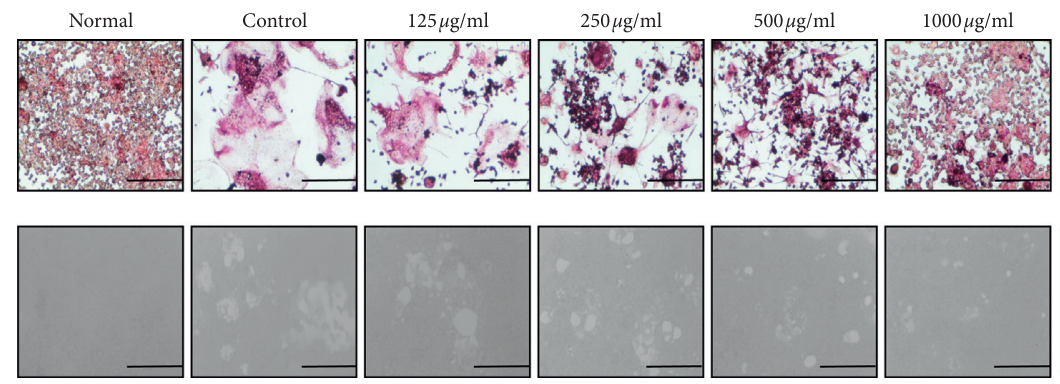

(c)

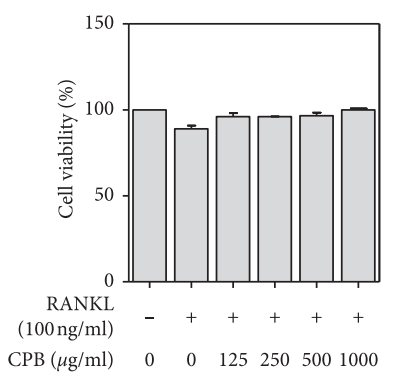

(b)

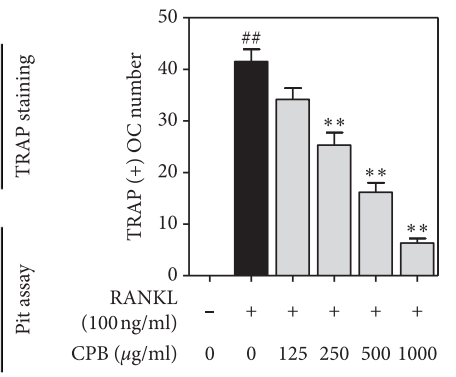

(d)

Figure 2: Continued. 


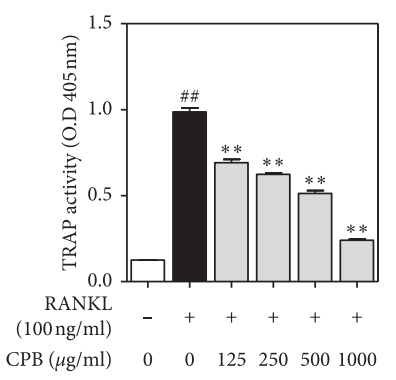

(e)

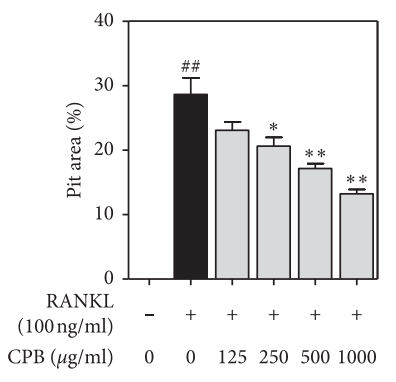

(f)

FIGURE 2: Effect of CPB on cell viability, osteoclast differentiation, and bone formation. (a) RAW 264.7 cells were measured by MTS assay of CPB treatment for $24 \mathrm{~h}$. (b) After differentiation into osteoclasts for 5 days, cytotoxicity was measured using MTS. (c) TRAP-positive cells and pit area were captured using an inverted microscope (100x, Scale bars: $200 \mu \mathrm{m})$. (d) TRAP-positive cells were counted with an inverted microscope. (e) TRAP activity was measured with an ELISA reader $(405 \mathrm{~nm})$. (f) The pit area was measured with ImageJ version 1.46 (100x, Scale bars: $200 \mu \mathrm{m})$. The results are presented as the mean \pm SEM $(n=3) .{ }^{\# \#} p<0.01$ compared to the normal group (untreated cells), and ${ }^{* *} p<0.01,{ }^{*} p<0.05$ compared to the control group (only-RANKL treated cells).

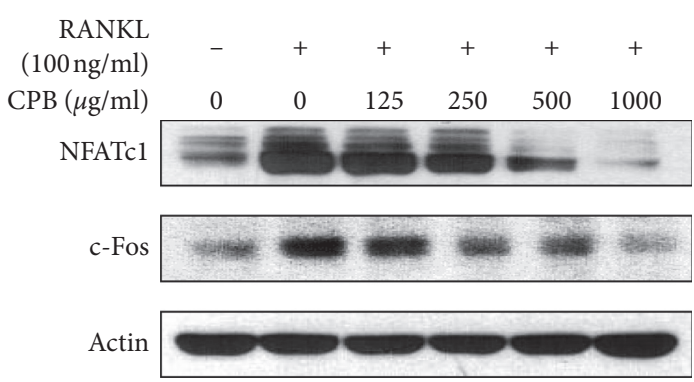

(a)

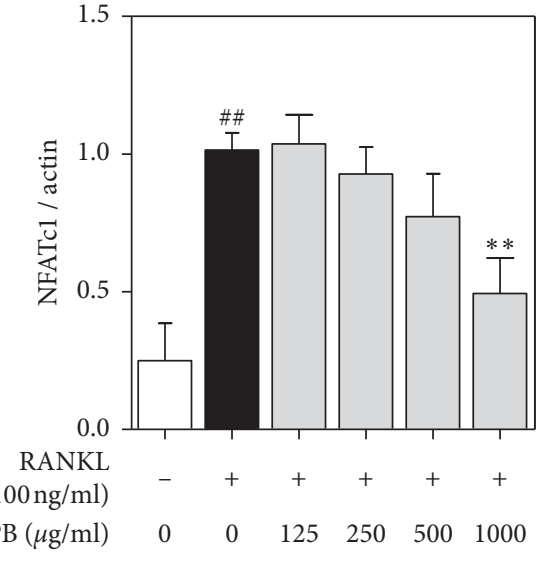

(b)

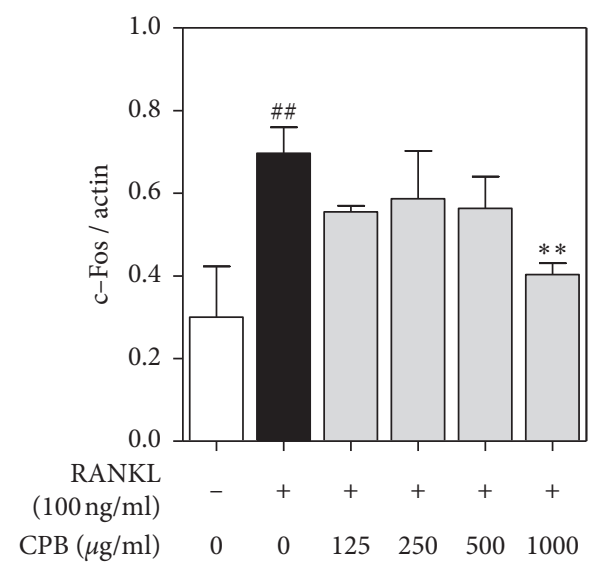

(c)

FIGURE 3: Effect of CPB extract on transcription factor such as NFATc1 and c-Fos. (a) RAW 264.7 cells were treated with RANKL (100 ng/ $\mathrm{mL}$ ) and CPB treatment for $24 \mathrm{~h}$. The expressions of NFATc1 and c-Fos were determined by western blotting. (b) NFATc1 and c-Fos were normalized to Actin with ImageJ version 1.46. The results are presented as the mean \pm SEM $(n=3)$. \#\# $p<0.01$ compared to the normal group (untreated cells), and ${ }^{* *} p<0.01,{ }^{*} p<0.05$ compared to the control group (only-RANKL treated cells).

analysis, BMD was significantly decreased in the OVX group compared to sham (Figure 6(b)), while in $\mathrm{E}_{2}$ and CPB-H groups, BMD increased compared with the OVX group. As shown in Figure 6(c), BV/TV was decreased in the OVX group compared with the sham group. $\mathrm{E}_{2}$ significantly increased BV/TV compared to the OVX group. CPB-L and 

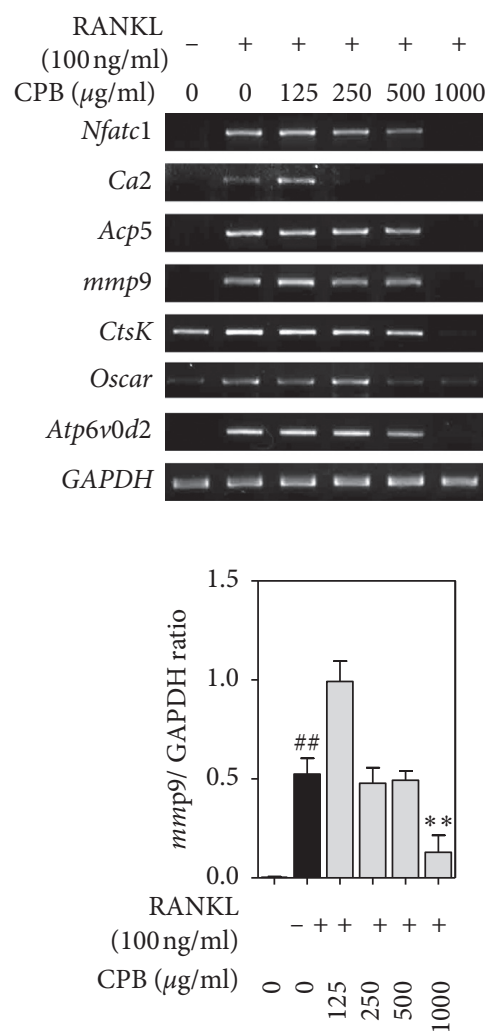

(a)

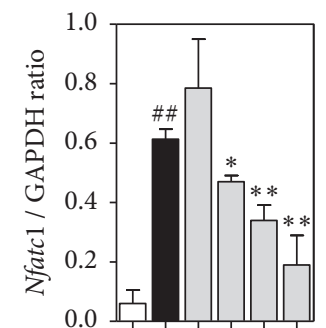

RANKL

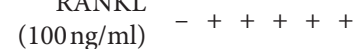

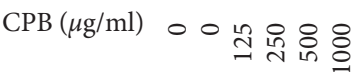

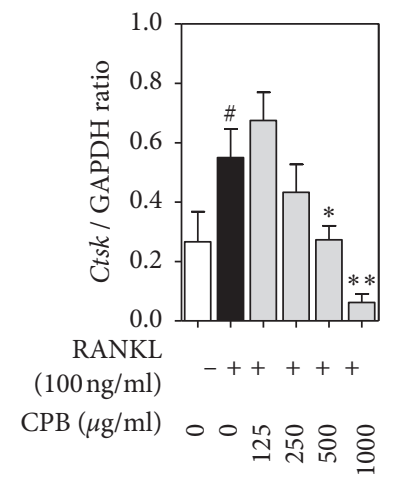

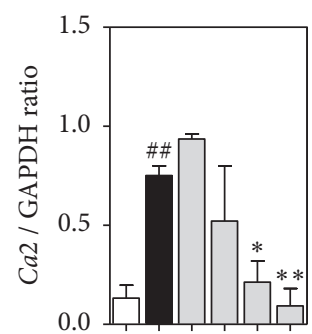

RANKL

$(100 \mathrm{ng} / \mathrm{ml})$

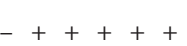

CPB $(\mu \mathrm{g} / \mathrm{ml})$

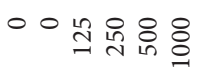

RANKL

$(100 \mathrm{ng} / \mathrm{ml})-++++$

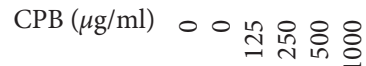

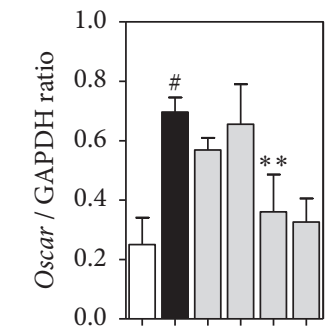

RANKL

$(100 \mathrm{ng} / \mathrm{ml})$
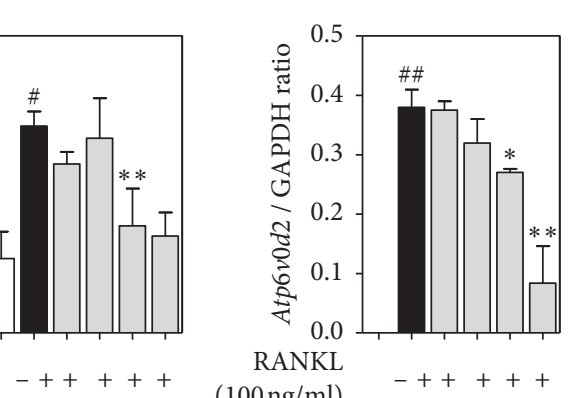

RANKL

$(100 \mathrm{ng} / \mathrm{ml})$

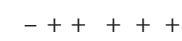

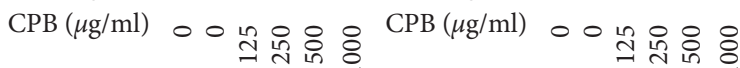

(b)

Figure 4: Effect of CPB extract on osteoclast-related genes. (a) RAW 264.7 cells were treated with RANKL (100 ng/mL) and CPB treatment for 4 days. RT-qPCR was used to determine the mRNA levels of osteoclast-related genes. (b) The levels of mRNA were normalized to GAPDH. The results are presented as the mean \pm SEM $(n=3) .{ }^{\# \#} p<0.01,{ }^{\#} p<0.05$ compared to the normal group (untreated cells), and ${ }^{* *} p<0.01,{ }^{*} p<0.05$ compared to the control group (only-RANKL treated cells).

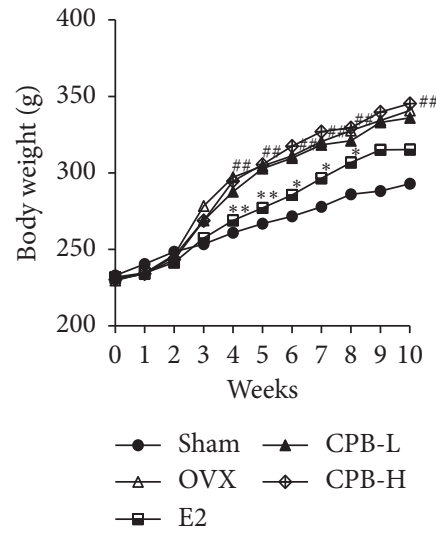

(a)
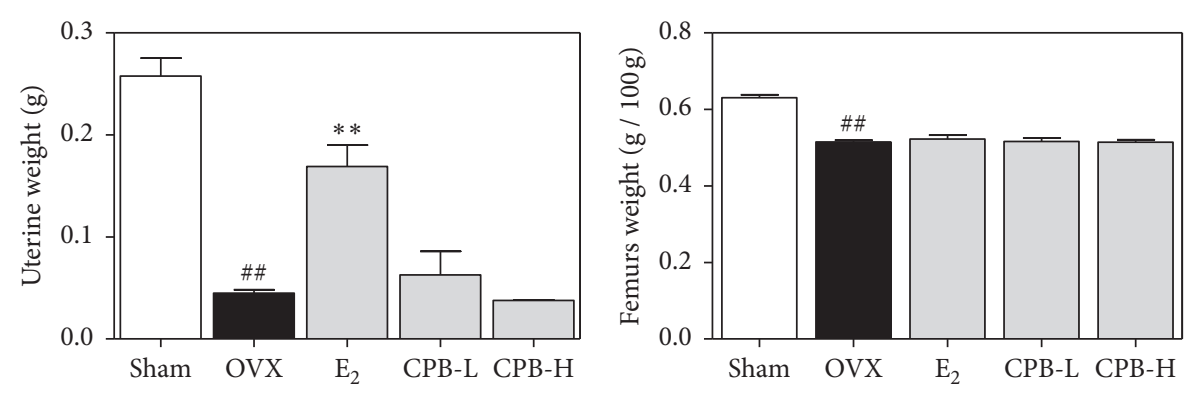

(b)

(c)

FIgURE 5: Continued. 


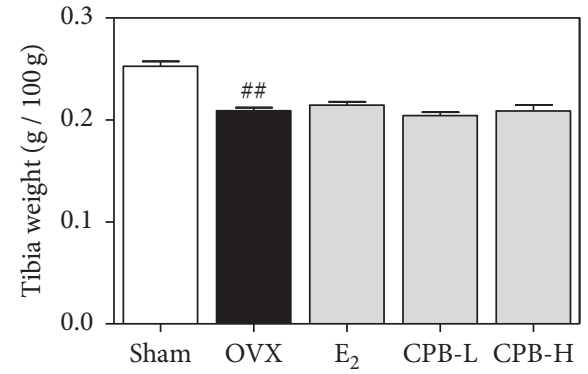

(d)

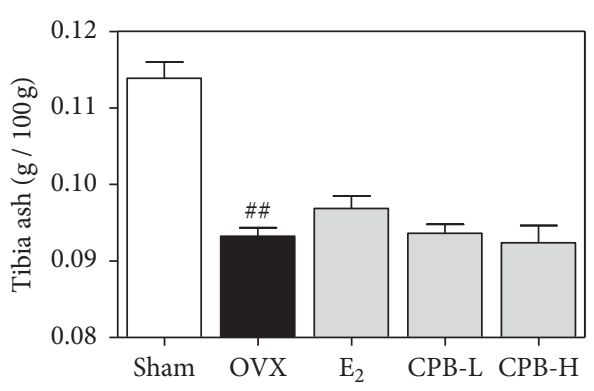

(e)

FIGURE 5: Effect of CPB on OVX-induced model. (a) The body weight was measured once a week. (b) Uterus weight, (c) femurs weight, (d) tibia weight, and (e) tibia ash was measured after sacrifice. The results are presented as the mean \pm SEM of each experimental group $(n=8)$. ${ }^{\# \#} p<0.01,{ }^{\#} p<0.05$ compared to the normal group (sham group), and ${ }^{* *} p<0.01,{ }^{*} p<0.05$ compared to the control group (OVX group).
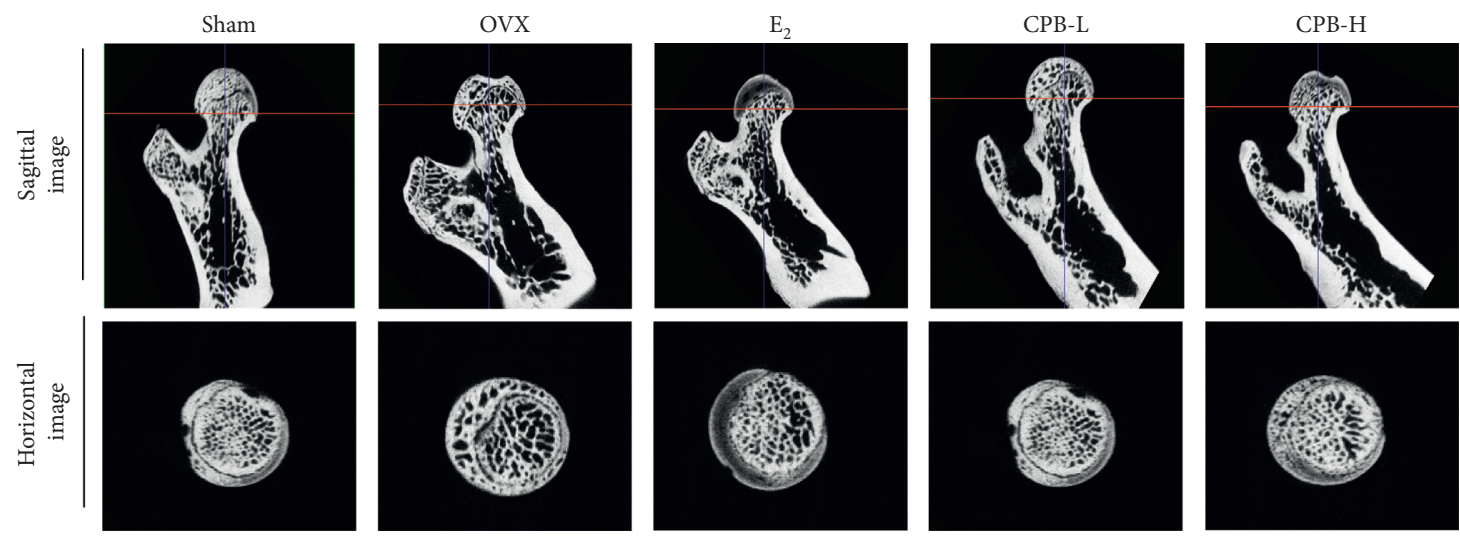

(a)

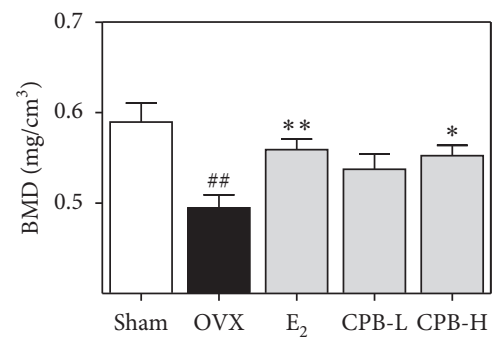

(b)

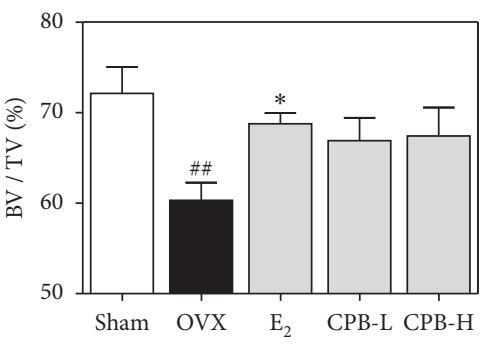

(c)

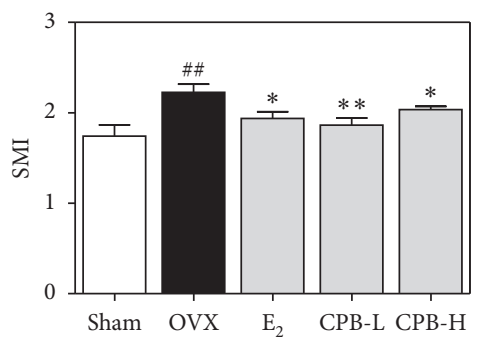

(d)

Figure 6: Effect of CPB on an osteoporosis rat model. (a) Analysis of micro-CT in the femoral head. The bone microstructure parameters, such as (b) BMD, (c) BV/TV, and (d) SMI, were measured by micro-CT. The results are presented as the mean \pm SEM for each experimental group ( $n=8) .{ }^{\# \#} p<0.01,{ }^{\#} p<0.05$ compared to the normal group (sham group), and ${ }^{* *} p<0.01,{ }^{*} p<0.05$ compared to the control group (OVX group).

CPB-H groups had increased BV/TV but not significantly. In addition, SMI was increased in the OVX group compared to the sham group (Figure 6(d)). In contrast, SMI was reduced in all three groups: $\mathrm{E}_{2}, \mathrm{CPB}-\mathrm{L}$, and CPB-H, compared to the OVX group.

\subsection{Effect of CPB on Trabecular Area and Expression of CTK in} the Femoral Head. To measure the trabecular area, bone tissues were stained with H\&E (Figure $7(\mathrm{a})$ ). To determine the effect of CPB treatments on the CTK in OVX-induced rats, we perform the IHC staining (Figure $7(\mathrm{~b})$ ). The trabecular area was decreased in the OVX group when compared with that of the sham group. Treatments with $\mathrm{E}_{2}, \mathrm{CPB}-$ $\mathrm{L}$, and $\mathrm{CPB}-\mathrm{H}$ inhibited the loss of the trabecular area compared with that of the OVX group (Figure $7(\mathrm{c})$ ). Furthermore, OVX groups significantly increased CTK compared to the sham group. Concurrently, $\mathrm{E}_{2}, \mathrm{CPB}-\mathrm{L}$, and CPB-H groups reduced CTK compared to the OVX group (Figure $7(\mathrm{~d})$ ). 

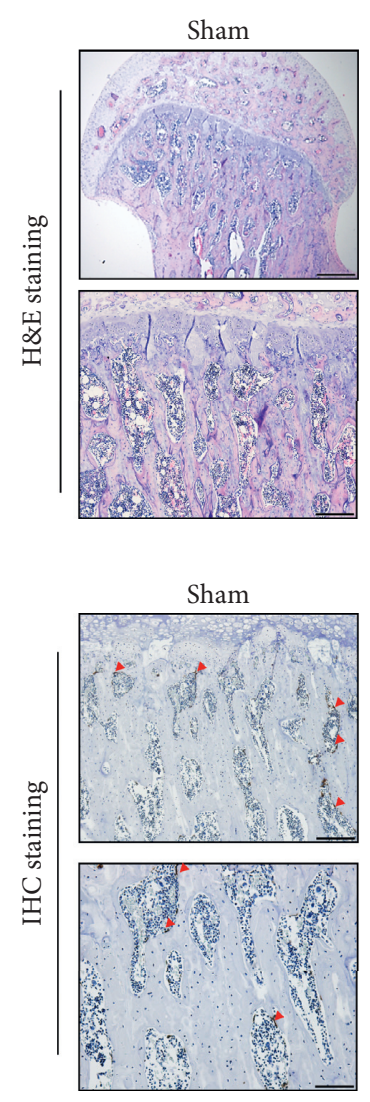

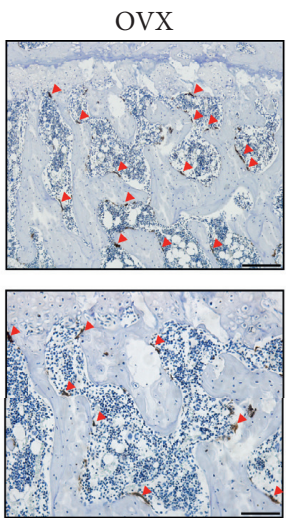

$\mathrm{E}_{2}$
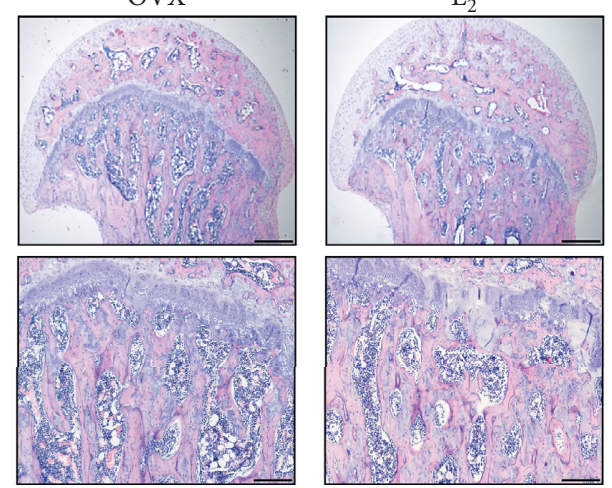

(a)
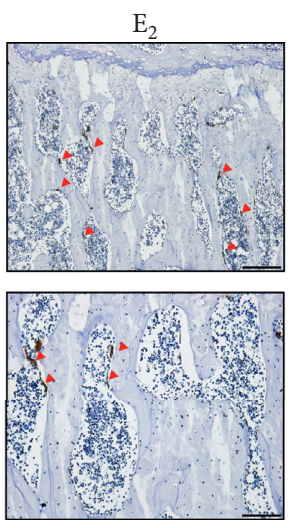

CPB-L
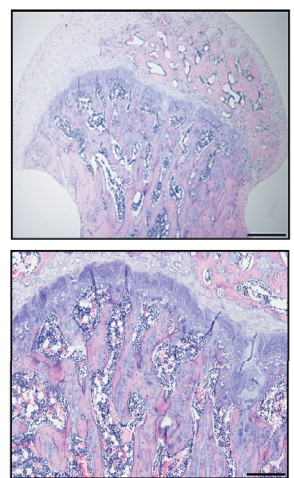

CPB-L
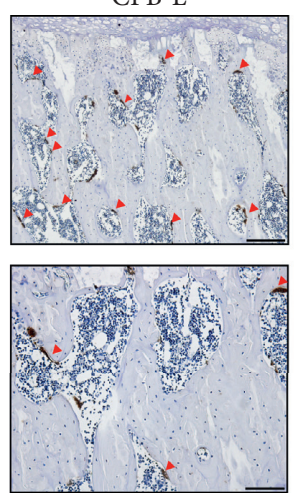

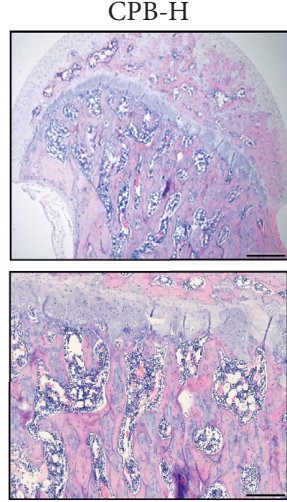

CPB-H
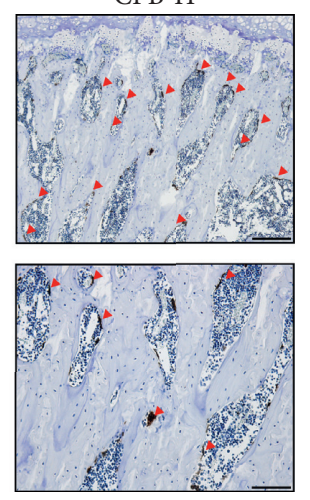

(b)

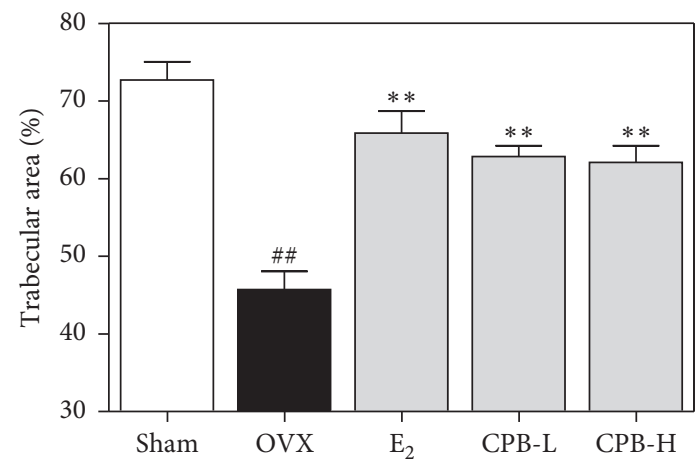

(c)

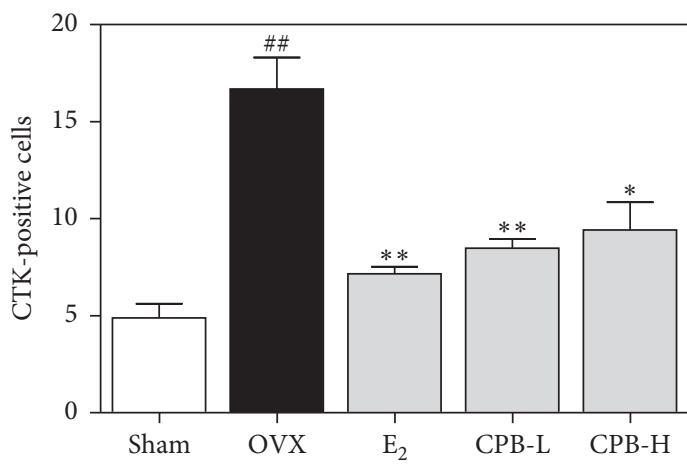

(d)

FIGURE 7: Effect of CPB on OVX-induced bone loss model. (a) The histology of the bone tissues was examined using H\&E staining, and (b) IHC staining. (c) The trabecular area was measured using ImageJ version 1.46. (d) CTK-positive cells were counted using ImageJ version 1.46. CTK-positive cells are indicated by red arrows. The results are presented as the mean \pm SEM for each experimental group $(n=8)$. ${ }^{\# \#} p<0.01,{ }^{\#} p<0.05$ compared to the normal group (sham group), and ${ }^{* *} p<0.01,{ }^{*} p<0.05$ compared to the control group (OVX group).

\section{Discussion}

According to recent studies, various side effects have been reported with the administration of bisphosphonate and SERM, which are currently used for the treatment of osteoporosis. This has prompted many researchers to search for safer alternative medicinal agents with fewer side effects for osteoporosis treatment [7-10]. In this study, we examined the osteoclastogenesis and antiosteoporosis effects of CPB on RAW 264.7 cells. In vitro, $\mathrm{CPB}$ demonstrated an inhibitory effect on osteoclast differentiation by inhibiting transcription factors and osteoclast-related genes. In vivo, $\mathrm{CPB}$ also prevented bone loss in OVX-induced rat models.

TRAP is a known osteoclast phenotype marker, and TRAP staining is a standard method used to determine osteoclast expression and activation $[21,22]$. In the present study, TRAP staining results showed a significant decrease in TRAP-positive cells and TRAP activity following CPB treatment. Pit formation is commonly used to measure the osteoclasts' differentiation and bone resorption ability $[23,24]$. As a result of the experiment, CPB significantly 
suppressed the pit area. It is unclear whether $\mathrm{CPB}$ reduces pit formation by inhibiting the ability of osteoclasts to bone resorption, or it controls pit formation by inhibiting osteoclast differentiation, but the TRAP staining and pit assay results, $\mathrm{CPB}$, seem to regulate bone resorption by inhibiting osteoclast differentiation.

Transcription factors, such as NFATc1 and c-Fos, are essential in osteoclast differentiation $[25,26]$. In a previous study, c-Fos-deficient cells were not able to differentiate into osteoclasts [11]. In contrast, excessive expression of c-Fos causes osteosarcoma and chondrosarcoma [27]. Furthermore, NFATc1-deficient mice develop osteopetrosis due to blocked osteoclast differentiation [28]. It has also been reported that embryonic stem cells deficient in NFATc1 cannot differentiate into osteoclasts upon RANKL stimulation [29]. Therefore, c-Fos and NFATc1 are important factors for osteoclast differentiation $[25,26]$. The present study showed that CPB significantly decreased the expression of c-Fos and NFATc1 and subsequent osteoclast differentiation.

c-Fos regulates bone resorption markers, such as CA2, which acidifies the bone surface during bone resorption [30-32]. Furthermore, NFATc1 regulates the expression of osteoclast-specific genes such as TRAP, MMP-9, CTK, ATP6v0d2, and OSCAR [25]. MMP-9 and CTK are involved in the process of osteoclast differentiation and play an important role in osteoclast precursors and bone resorption $[6,33,34]$. MMP-9 has a negative correlation with BMD, and overexpression of MMP-9 attenuates osteoclast formation $[35,36]$. CTK is a cysteine proteinase mainly expressed in osteoclasts. CTK is known to play an important role in breaking down the organic phases of bone during bone resorption [37]. According to previous studies, a deficiency of CTK indicates an osteoporosis phenotype [38]. Therefore, it was found that the deficiency of CTK is associated with the inhibition of osteoclast activity, and CTK is an effective target in the treatment of osteoporosis. ATP6v0d2 is an essential factor required for cell-cell fusion. Previous studies found ATP6v0d2-deficient mice present with an osteopetrosis phenotype due to abnormal osteoclast maturation $[39,40]$. OSCAR regulates osteoclast differentiation and cell maturation and is a costimulatory receptor for osteoclast differentiation through activation of NFATc1. It is known that OSCAR may contribute to the etiology and severity of osteoporosis and rheumatoid arthritis [41, 42]. The present study showed that CPB significantly decreased the expression of osteoclast-related genes (Nfatc1, Ca2, Acp5, mmp9, CtsK, Oscar, and Atp6v0d2) in RANKL-induced osteoclast differentiation in RAW 264.7 cellsvia regulation of c-Fos and NFATc1 signaling.

OVX-induction is widely used in postmenopausal osteoporosis research. According to a previous study, OVXinduced rats share similar symptoms to human osteoporosis, such as the increase in body weight [43]. In addition, loss of uterus weight demonstrates that the postmenopausal osteoporosis model had been successfully established [44, 45]. In this study, all OVX-induced rats, including $\mathrm{CPB}$ and $\mathrm{E}_{2}$ treatment, increased body weight from week 4 , while all groups, except for the $\mathrm{E}_{2}$-treatment, had decreased uterus weight. These results confirm previous studies that $\mathrm{E}_{2}$ treatment reverses the effect of postmenopausal changes to uterus weight, while CPB had no effect in this regard.

Micro-CT is used to analyze the structural properties of bones in three dimensions [46, 47]. Bone density and bone microstructure are indicators used to evaluate bone quality [48]. BV/TV represents the volume of bone within the volume of interest (VOI), whereas SMI refers to the structural morphology index of the cancellous bone $[48,49]$. According to a recent study, increased BMD is not sufficient to improve or prevent osteoporosis [50]. Therefore, SMI is a complimentary representative index used for accurate bone quality assessment. In this study, the reduction in BMD, BV/ $\mathrm{TV}$, and SMI was improved by the administration of $\mathrm{E}_{2}$ and $\mathrm{CPB}-\mathrm{H}$. These results suggest that $\mathrm{CPB}$ can be a treatment for postmenopausal osteoporosis through the prevention of bone loss.

As a result of histological examination, we showed that $\mathrm{E}_{2}$ and $\mathrm{CPB}$ treatment prevented the decrease in the trabecular area, indicating that $\mathrm{CPB}$ inhibits bone loss of postmenopausal osteoporosis. IHC staining was used to measure the expression of bone-related factors in tissues. In this study, $\mathrm{E}_{2}, \mathrm{CPB}-\mathrm{L}$, and $\mathrm{CPB}-\mathrm{H}$ groups suppressed the expression of CTK induced by OVX. Furthermore, this also correlates with the findings of the in vitro experiments. These results further suggest that $\mathrm{CPB}$ inhibits bone resorption. In summary, CPB has antiosteoporotic effects on OVX-induced rats by suppressing $\mathrm{BMD}$ and bone resorption markers such as CTK.

The limitations of this study are as follows: (i) MAPK and $\mathrm{NF}-\kappa \mathrm{B}$ signaling pathways play an important role in NFATc1 and c-Fos activation. In this study, CPB significantly inhibited the expression of NFATc1 and c-Fos, but MAPK and NF- $\kappa$ B pathways were not studied. Therefore, it is still necessary to correlate the inhibitory effect of $\mathrm{CPB}$ to the MAPK and NF- $\kappa \mathrm{B}$ signaling pathways. (ii) As patients with osteoporosis have already lost a certain amount of bone density, it is important to also promote osteoblast activity to restore the lost bone mass, along with osteoclast activity inhibitors to prevent disease progression. Therefore, future studies should focus on the effects of $\mathrm{CPB}$ on promoting osteoblast differentiation. (iii) Treatment of osteoporosis remains focused on postmenopausal osteoporosis in type 1 osteoporosis. However, interest in male osteoporosis and senile osteoporosis is also increasing. Therefore, studies on CPB in other osteoporosis models are also required.

\section{Conclusion}

In this study, CPB effectively inhibited osteoclast differentiation in vitro and prevented bone loss in vivo. The mechanisms of inhibition were via suppression of osteoporosis-related protein expression (NFATc1 and c-Fos), gene expression (Nfatc1, Ca2, Acp5, mmp9, CtsK, Oscar, and $A t p 6 v 0 d 2$ ), and inhibited bone loss induced in the OVX model. These results indicate that CPB may be useful in the treatment of metabolic bone diseases such as osteoporosis. 


\section{Abbreviations}

SERM: Selective estrogen receptor modulators

CPB: $\quad$ Crataegus pinnatifida Bunge

OVX: Ovariectomized

Micro- Microcomputed tomography

CT:

RANKL: Receptor activator of nuclear factor Kappa-B ligand

TRAF6: TNF receptor-associated factor 6

MAPK: Mitogen-activated protein kinase

NFATc1: Nuclear factor-activated T cells c1

DMEM: Dulbecco's modified eagle's medium

$\alpha$-MEM: Minimum essential medium eagle alphamodification

DPBS: Dulbecco's phosphate buffered saline

FBS: $\quad$ Fetal bovine serum

BCA: Bicinchoninic acid

$\mathrm{E}_{2}$ : $\quad 17 \beta$-estradiol

MTS: $\quad$ Cell titer $96^{\circledR}$ aqueous nonradioactive cell proliferation assay

ABC: $\quad$ Avidin-biotin complex

DAB: $\quad 3,3^{\prime}$-diaminobenzidine

DW: Distilled water

HPLC: High-performance liquid chromatography

SD-rat: Sprague-Dawley rat

BMD: Bone mineral density

BV/TV: Bone volume/total volume

SMI: $\quad$ Structure model index

H\&E: Hematoxylin and eosin

EDTA: Ethylenediaminetetraacetic acid

IHC: Immunohistochemistry.

\section{Data Availability}

All data generated or analyzed during this study are included in this published article.

\section{Conflicts of Interest}

The authors declare that they have no conflicts of interest.

\section{Authors' Contributions}

Minsun Kim and MinBeom Kim contributed equally to this work.

\section{Acknowledgments}

This work was supported by the National Research Foundation of Korea (NRF) grant funded by the Korea government (MSIT) (nos. 2020R1A2C1007836 and 2019R1H1A2101224).

\section{References}

[1] NIH Consensus Development Panel on Osteoporosis Prevention and Therapy, "Osteoporosis prevention, diagnosis, and therapy," JAMA, vol. 285, no. 6, pp. 785-795, 2001.

[2] J. A. Kanis, L. J. Melton III, C. Christiansen, C. C. Johnston, and N. Khaltaev, "The diagnosis of osteoporosis," Journal of
Bone and Mineral Research: The Official Journal of the American Society for Bone and Mineral Research, vol. 9, no. 8, pp. 1137-1141, 1994.

[3] B. F. Boyce, "Advances in the regulation of osteoclasts and osteoclast functions," Journal of Dental Research, vol. 92, no. 10, pp. 860-867, 2013.

[4] B. F. Boyce and L. Xing, "Functions of RANKL/RANK/OPG in bone modeling and remodeling," Archives of Biochemistry and Biophysics, vol. 473, no. 2, pp. 139-146, 2008.

[5] W. J. Boyle, W. S. Simonet, and D. L. Lacey, "Osteoclast differentiation and activation," Nature, vol. 423, no. 6937, pp. 337-342, 2003.

[6] K. Fujisaki, N. Tanabe, N. Suzuki et al., "Receptor activator of $\mathrm{NF}-\kappa \mathrm{B}$ ligand induces the expression of carbonic anhydrase II, cathepsin K, and matrix metalloproteinase-9 in osteoclast precursor RAW264.7 cells," Life Sciences, vol. 80, no. 14, pp. 1311-1318, 2007.

[7] K. A. Kennel and M. T. Drake, "Adverse effects of bisphosphonates: implications for osteoporosis management," Mayo Clinic Proceedings, vol. 84, no. 7, pp. 632-638, 2009.

[8] N. B. Watts and D. L. Diab, "Long-term use of bisphosphonates in osteoporosis," The Journal of Clinical Endocrinology \& Metabolism, vol. 95, no. 4, pp. 1555-1565, 2010.

[9] M. McClung, S. T. Harris, P. D. Miller et al., "Bisphosphonate therapy for osteoporosis: benefits, risks, and drug holiday," The American Journal of Medicine, vol. 126, no. 1, pp. 13-20, 2013.

[10] K.-C. An, "Selective estrogen receptor modulators," Asian Spine Journal, vol. 10, no. 4, pp. 787-791, 2016.

[11] K. Matsuo, D. L. Galson, C. Zhao et al., "Nuclear factor of activated T-cells (NFAT) rescues osteoclastogenesis in precursors lacking c-Fos," Journal of Biological Chemistry, vol. 279, no. 25, pp. 26475-26480, 2004.

[12] E. S. Kao, C. J. Wang, W. L. Lin, Y. F. Yin, C. P. Wang, and T. H. Tseng, "Anti-inflammatory potential of flavonoid contents from dried fruit of Crataegus pinnatifida in vitro and in vivo," Journal of Agricultural and Food Chemistry, vol. 53, no. 2, pp. 430-436, 2005.

[13] I. S. Shin, M. Y. Lee, H. S. Lim et al., "An extract of Crataegus pinnatifida fruit attenuates airway inflammation by modulation of matrix metalloproteinase- 9 in ovalbumin induced asthma," PLoS One, vol. 7, no. 9, Article ID e45734, 2012.

[14] S. C. Kwak, C. Lee, J.-Y. Kim et al., "Chlorogenic acid inhibits osteoclast differentiation and bone resorption by down-regulation of receptor activator of nuclear factor kappa-B ligandinduced nuclear factor of activated T cells c1 expression," Biological and Pharmaceutical Bulletin, vol. 36, no. 11, pp. 1779-1786, 2013.

[15] S. J. Hwang, Y.-W. Kim, Y. Park, H.-J. Lee, and K.-W. Kim, "Anti-inflammatory effects of chlorogenic acid in lipopolysaccharide-stimulated RAW 264.7 cells," Inflammation Research, vol. 63, no. 1, pp. 81-90, 2014.

[16] D. Cheng, X. Zhang, J. Tang, Y. Kong, X. Wang, and S. Wang, "Chlorogenic acid protects against aluminum toxicity via MAPK/Akt signaling pathway in murine RAW264.7 macrophages," Journal of Inorganic Biochemistry, vol. 190, pp. 113-120, 2019.

[17] L. Ginaldi, M. C. Di Benedetto, and M. De Martinis, "Osteoporosis, inflammation and ageing," Immunity and Ageing, vol. 2, p. 14, 2009.

[18] G. R. Mundy, "Osteoporosis and inflammation," Nutrition Reviews, vol. 65, no. 12, pp. S147-S151, 2007. 
[19] M. H. Tschöp, J. R. Speakman, J. R. S. Arch et al., "A guide to analysis of mouse energy metabolism," Nature Methods, vol. 9, no. 1, pp. 57-63, 2011.

[20] T. Jurikova, J. Sochor, O. Rop et al., "Polyphenolic profile and biological activity of Chinese hawthorn (Crataegus pinnatifida BUNGE) fruits," Molecules, vol. 17, no. 12, pp. 14490-14509, 2012.

[21] A. R. Hayman, "Tartrate-resistant acid phosphatase (TRAP) and the osteoclast/immune cell dichotomy," Autoimmunity, vol. 41, no. 3, pp. 218-223, 2008.

[22] C. Minkin, "Bone acid phosphatase: tartrate-resistant acid phosphatase as a marker of osteoclast function," Calcified Tissue International, vol. 34, no. 3, pp. 285-290, 1982.

[23] S. L. Teitelbaum, "Bone resorption by osteoclasts," Science, vol. 289, no. 5484, pp. 1504-1508, 2000.

[24] K. Fuller, J. T. Thong, B. C. Breton, and T. J. Chambers, "Automated three-dimensional characterization of osteoclastic resorption lacunae by stereoscopic scanning electron microscopy," Journal of Bone and Mineral Research, vol. 9, no. 1, pp. 17-23, 1994.

[25] Q. Zhao, X. Wang, Y. Liu, A. He, and R. Jia, "NFATc1: functions in osteoclasts," The International Journal of Biochemistry \& Cell Biology, vol. 42, no. 5, pp. 576-579, 2010.

[26] A. Grigoriadis, Z. Wang, M. Cecchini et al., "c-Fos: a key regulator of osteoclast-macrophage lineage determination and bone remodeling," Science, vol. 266, no. 5184, pp. 443-448, 1994.

[27] A. Abarrategi, S. Gambera, A. Alfranca et al., "c-Fos induces chondrogenic tumor formation in immortalized human mesenchymal progenitor cells," Scientific Reports, vol. 8, no. 1, p. 15615, 2018.

[28] A. O. Aliprantis, Y. Ueki, R. Sulyanto et al., "NFATc1 in mice represses osteoprotegerin during osteoclastogenesis and dissociates systemic osteopenia from inflammation in cherubism," Journal of Clinical Investigation, vol. 118, no. 11, pp. 3775-3789, 2008.

[29] H. Takayanagi, S. Kim, T. Koga et al., "Induction and activation of the transcription factor NFATc1 (NFAT2) integrate RANKL signaling in terminal differentiation of osteoclasts," Developmental Cell, vol. 3, no. 6, pp. 889-901, 2002.

[30] D. M. Biskobing, D. Fan, X. Fan, and J. Rubin, "Induction of carbonic anhydrase II expression in osteoclast progenitors requires physical contact with stromal cells," Endocrinology, vol. 138, no. 11, pp. 4852-4857, 1997.

[31] E. C. Seales, K. J. Micoli, and J. M. McDonald, "Calmodulin is a critical regulator of osteoclastic differentiation, function, and survival," Journal of Cellular Biochemistry, vol. 97, no. 1, pp. 45-55, 2006.

[32] M. J. Berridge, M. D. Bootman, and H. L. Roderick, "Calcium signalling: dynamics, homeostasis and remodelling," Nature Reviews Molecular Cell Biology, vol. 4, no. 7, pp. 517-529, 2003.

[33] T. Ohshiba, C. Miyaura, M. Inada, and A. Ito, "Role of RANKL-induced osteoclast formation and MMP-dependent matrix degradation in bone destruction by breast cancer metastasis," British Journal of Cancer, vol. 88, no. 8, pp. 1318-1326, 2003.

[34] P. Garnero, O. Borel, I. Byrjalsen et al., "The collagenolytic activity of cathepsin $\mathrm{K}$ is unique among mammalian proteinases," Journal of Biological Chemistry, vol. 273, no. 48, pp. 32347-32352, 1998.

[35] A. I. Alford, K. M. Kozloff, and K. D. Hankenson, "Extracellular matrix networks in bone remodeling," The
International Journal of Biochemistry \& Cell Biology, vol. 65, pp. 20-31, 2015.

[36] J. Guo, X. Zeng, J. Miao et al., "MiRNA-218 regulates osteoclast differentiation and inflammation response in periodontitis rats through Mmp9," Cellular Microbiology, vol. 21, no. 4, Article ID e12979, 2019.

[37] P. D’Agostino, M. C. Faniello, B. Quaresima et al., "Negative and positive elements in the promoter region of the human apoferritin L gene," Biochemical and Biophysical Research Communications, vol. 215, no. 1, pp. 329-337, 1995.

[38] E. Kozawa, Y. Nishida, X. W. Cheng et al., "Osteoarthritic change is delayed in a Ctsk-knockout mouse model of osteoarthritis," Arthritis \& Rheumatism, vol. 64, no. 2, pp. 454-464, 2012.

[39] S.-H. Lee, J. Rho, D. Jeong et al., "v-ATPase V0 subunit d2deficient mice exhibit impaired osteoclast fusion and increased bone formation," Nature Medicine, vol. 12, no. 12, pp. 1403-1409, 2006.

[40] K. Kim, S.-H. Lee, J. Ha Kim, Y. Choi, and N. Kim, "NFATc1 induces osteoclast fusion via up-regulation of Atp6v0d2 and the dendritic cell-specific transmembrane protein (DCSTAMP)," Molecular Endocrinology, vol. 22, no. 1, pp. 176-185, 2008.

[41] K. Nemeth, M. Schoppet, N. Al-Fakhri et al., "The role of osteoclast-associated receptor in osteoimmunology," The Journal of Immunology, vol. 186, no. 1, pp. 13-18, 2011.

[42] S. Herman, R. B. Müller, G. Krönke et al., "Induction of osteoclast-associated receptor, a key osteoclast costimulation molecule, in rheumatoid arthritis," Arthritis \& Rheumatism, vol. 58, no. 10, pp. 3041-3050, 2008.

[43] R. G. Clark and M. F. Tarttelin, "Some effects of ovariectomy and estrogen replacement on body composition in the rat," Physiology \& Behavior, vol. 28, no. 6, pp. 963-969, 1982.

[44] D. N. Kalu, "The ovariectomized rat model of postmenopausal bone loss," Bone and Mineral, vol. 15, no. 3, pp. 175-191, 1991.

[45] W. S. Jee and W. Yao, "Overview: animal models of osteopenia and osteoporosis," Journal of Musculoskeletal \& Neuronal Interactions, vol. 1, no. 3, pp. 193-207, 2001.

[46] A. Laib, O. Barou, L. Vico, M. H. Lafage-Proust, C. Alexandre, and P. Rügsegger, "3D micro-computed tomography of trabecular and cortical bone architecture with application to a rat model of immobilisation osteoporosis," Medical \& Biological Engineering \& Computing, vol. 38, no. 3, pp. 326-332, 2000.

[47] M. L. Bouxsein, S. K. Boyd, B. A. Christiansen, R. E. Guldberg, K. J. Jepsen, and R. Müller, "Guidelines for assessment of bone microstructure in rodents using micro-computed tomography," Journal of Bone and Mineral Research, vol. 25, no. 7, pp. 1468-1486, 2010.

[48] Z. Lei, Z. Xiaoying, and L. Xingguo, "Ovariectomy-associated changes in bone mineral density and bone marrow haematopoiesis in rats," International Journal of Experimental $\mathrm{Pa}$ thology, vol. 90, no. 5, pp. 512-519, 2009.

[49] M. L. Brandi, "Microarchitecture, the key to bone quality," Rheumatology, vol. 48, no. 4, pp. iv3-iv8, 2009.

[50] A. Cranney, S. A. Jamal, J. F. Tsang, R. G. Josse, and W. D. Leslie, "Low bone mineral density and fracture burden in postmenopausal women," Canadian Medical Association Journal, vol. 177, no. 6, pp. 575-580, 2007. 